\title{
Are the Temporal Trends of Stomach Cancer Mortality in Brazil Similar to the Low, Middle, and High-Income Countries?
}

\author{
Samantha Hasegawa Farias *, Wilson Leite Maia Neto, Katia Pereira Tomaz, \\ Francisco Winter dos Santos Figueiredo and Fernando Adami \\ Epidemiology and Data Analysis Laboratory, Centro Universitário Saúde ABC, Santo André, Brazil
}

Keywords: epidemiology, stomach neoplasms, socioeconomic status, mortality, social inequalities

\section{INTRODUCTION}

OPEN ACCESS

Edited by:

MinJae Lee,

University of Texas Southwestern Medical Center, United States

Reviewed by:

Reza Malekzadeh,

Tehran University of Medical

Sciences, Iran

Masoud Amiri,

Erasmus Medical Center, Netherlands

*Correspondence:

Samantha Hasegawa Farias samanthahf@gmail.com

Specialty section: This article was submitted to Life-Course Epidemiology and Social Inequalities in Health,

a section of the journal Frontiers in Public Health

Received: 07 March 2021 Accepted: 14 May 2021

Published: 29 June 2021

Citation:

Farias SH, Maia Neto WL, Tomaz KP, Figueiredo FWdS and Adami F (2021) Are the Temporal Trends of Stomach Cancer Mortality in Brazil Similar to the

Low, Middle, and High-Income Countries?

Front. Public Health 9:677012. doi: 10.3389/fpubh.2021.677012
Stomach cancer is the fourth most common malignant tumor in the world, and although numbers have fallen in recent years, mortality from this cause is still high (1-3). In Brazil, some studies have shown a reduction in mortality from stomach cancer since the $1980 \mathrm{~s}(4,5)$, which can be attributed to improved eating habits, food preservation, and treatment of Helicobacter pylori infection $(6,7)$.

In addition, there were significant advances related to socioeconomic development and the reduction of inequalities and socioeconomic inequities, which improved the population's access to health care and reduced the morbidity and mortality of diseases such as breast cancer (8-10).

Brazil is a middle-income country characterized by great internal heterogeneity $(11,12)$. It is notorious that poverty in Brazil has a location (13) and, in terms of disparities, the country has a very striking feature that is the regional inequalities, where the north and northeast regions have the worst indicators. The central region has intermediate rates, and the south and southeast are the best conditions, regardless of the socioeconomic indicator being evaluated (14). These social inequalities in the country still today directly reflect on health inequality, explaining the unfavorable scenarios for the north and northeast, and a very evident polarization in relation to the south and southeast (15).

The country presents regions with different socioeconomic characteristics, which impacts health services, lifestyle, and socio-cultural aspects. In other words, there are developed regions with high technology for cancer-oriented health services and underdeveloped regions that cannot properly treat and diagnose its citizens (16).

Thus, considering that Brazil is a country with territorial extension of continental characteristics and high socioeconomic plurality, and that the mortality due to stomach cancer is related to the socioeconomic status of the site, what level of development does the behavior of stomach cancer mortality in Brazil follow?

Thus, the aim of this study was to describe the temporal trend of stomach cancer mortality in Brazil from 1990 to 2016, analyzing its behavior in relation to low, middle, and high income countries.

\section{METHODS}

\section{Study Design}

Secondary data analysis performed based on data from 1990 to 2016 obtained from the Global Burden of Disease (GBD). 


\section{Data Source}

The Global Burden of Disease database is coordinated by the Institute of Health Metrics and Evaluation (IHME) of the University of Washington and maintained through a partnership with researchers from 124 countries, with the objective of estimating the global burden of more than 300 diseases and injuries (17).

This database provides information from various sources based on official documents such as censuses, administrative databases, scientific publications, hospital and police records, among others. Through this information, there is a joint effort by scientific commissions from various countries to systematically quantify the magnitude of health loss due to diseases, injuries and risk factors by age, sex, and geographic location.

To facilitate the production of estimates and comparability of data, GBD researchers created a measure to classify the sociodemographic development of a locality, the Socio-demographic Index (SDI) (18), based on the average income per person, schooling, and total fertility rate to classify countries as low, medium low, medium, medium high, and high income.

\section{Study Variables}

The studied variables were deaths, age-standardized mortality, and proportional mortality from all cancer causes and proportional to all deaths. Data for Brazil and low, middle, and high income countries were adjusted for age and were expressed as rates (per 100,000 inhabitants). In the present study, only the low, middle, and high income classifications were evaluated, in order to better capture the differences between the analysis groups.

\section{Statistical Analysis}

Descriptive statistics were performed using the statistical program Stata ${ }^{\circledR}$ (StataCorp, L,C) version 11.0 and presented through absolute and relative frequency.

The time trend analysis was performed through the program Joinpoint Regression version 4.6.0 (Statistical Research and Applications Branch, National Cancer Institute, Rockville, EUA) (19). The joinpoint regression is a technique that explores the relationship between two variables by means of segmented linear regression. It determines the magnitude of change in the trend in percentage terms and verifies whether or not this change is statistically significant (20).

The final model chosen was the one with the highest number of points and maintained the statistical significance $(p<0.05)$. From the estimated slope for each straight line (regression coefficient), the Annual Percentage Change (APC) and Average Annual Percentage Change (AAPC) were calculated and its statistical significance was estimated by the Least Squares Method by a generalized linear model and for each straight line segment, with an estimated slope, and their $95 \%$ confidence intervals.

\section{Ethical Aspects}

According to Resolution No. 510 of April 7, 2016 of the National Health Council of Brazil, since these are public data and of free access. There is no need for ethical appreciation.
TABLE 1 | Mean mortality rates and age-adjusted mortality rates due to stomach cancer, proportional mortality for all deaths and proportional mortality for all cancers, 1990-2016.

\begin{tabular}{|c|c|c|c|c|}
\hline \multirow[t]{2}{*}{ Place } & \multirow{2}{*}{$\begin{array}{l}\text { Mortality } \\
\text { rate }^{a}\end{array}$} & \multirow{2}{*}{$\begin{array}{l}\text { Age-standardized } \\
\text { Mortality rate }^{a}\end{array}$} & \multicolumn{2}{|c|}{ Proportional mortality (\%) } \\
\hline & & & All deaths & All cancers \\
\hline Brazil & 13,10 & 15,54 & 1,60 & 9,74 \\
\hline \multicolumn{5}{|c|}{ Socioeconomic status } \\
\hline Low income & 11,06 & 11,12 & 0,38 & 8,01 \\
\hline $\begin{array}{l}\text { Middle } \\
\text { income }\end{array}$ & 17,16 & 24,70 & 2,31 & 12,37 \\
\hline High income & 10,78 & 12,04 & 1,94 & 7,44 \\
\hline
\end{tabular}

a Per 100,000 inhabitants.

\section{RESULTS}

There were $14,139,731$ deaths from stomach cancer in the high, middle, and low income countries between 1990 and 2016 , of which 612,818 were in low-income countries, $9,137,851$ in middle-income countries and 4,389,062 in high-income countries. In Brazil, there were 449,682 deaths in the same period.

With regard to socioeconomic status, stomach cancer mainly affects middle-income countries. In these countries, $\sim 25$ people die from stomach cancer per 100,000 inhabitants, representing $2.3 \%$ of all deaths from known causes and $12.3 \%$ of deaths from some form of cancer. In Brazil, the burden of stomach cancer appears to be lower than that observed in middleincome countries (15.5 deaths per 100,000 inhabitants, mortality proportional to all deaths of $1.6 \%$, and all cancers of $9.7 \%$ ) (Table 1).

It was observed that, regardless of the socioeconomic status, there is a decrease in the mortality rates due to stomach cancer in the studied sites. Throughout the study time, the rates decreased more in high income countries, while the middle income countries had greater variability (Figure 1).

In the first period of change corresponding to the years between 1990 and 2003, Brazil presented the annual percentage change (APC) of -1.8 (95\% CI $-1.9 ;-1.7)$, behavior of low and middle-income countries, which presented the same changes in their respective first periods of change. The second period of change observed in Brazil corresponded to the years of 20032015 and had APC of -2.8 (95\% CI $-3.0 ;-2.7)$, behavior close to high-income countries, which presented APC of -2.5 (95\% CI -2.6 ; -2.4) (Table 2).

When analyzing the average of the annual percentage change, we observed that the low-income countries had the lowest fall with the AAPC of $-1.4(95 \%$ CI $-1.5 ;-1.3)$, followed by middleincome $-2.1(95 \% \mathrm{CI}-2.1 ;-2.0)$ and high income countries $-2.7(95 \%$ CI $-2.8 ;-2.6)$. Brazil presented AAPC of $-2.3(95 \%$ CI $-2.4 ;-2.2)$.

\section{DISCUSSION}

Between 1990 and 2016, there was a downward trend in ageadjusted mortality from stomach cancer in all socioeconomic 


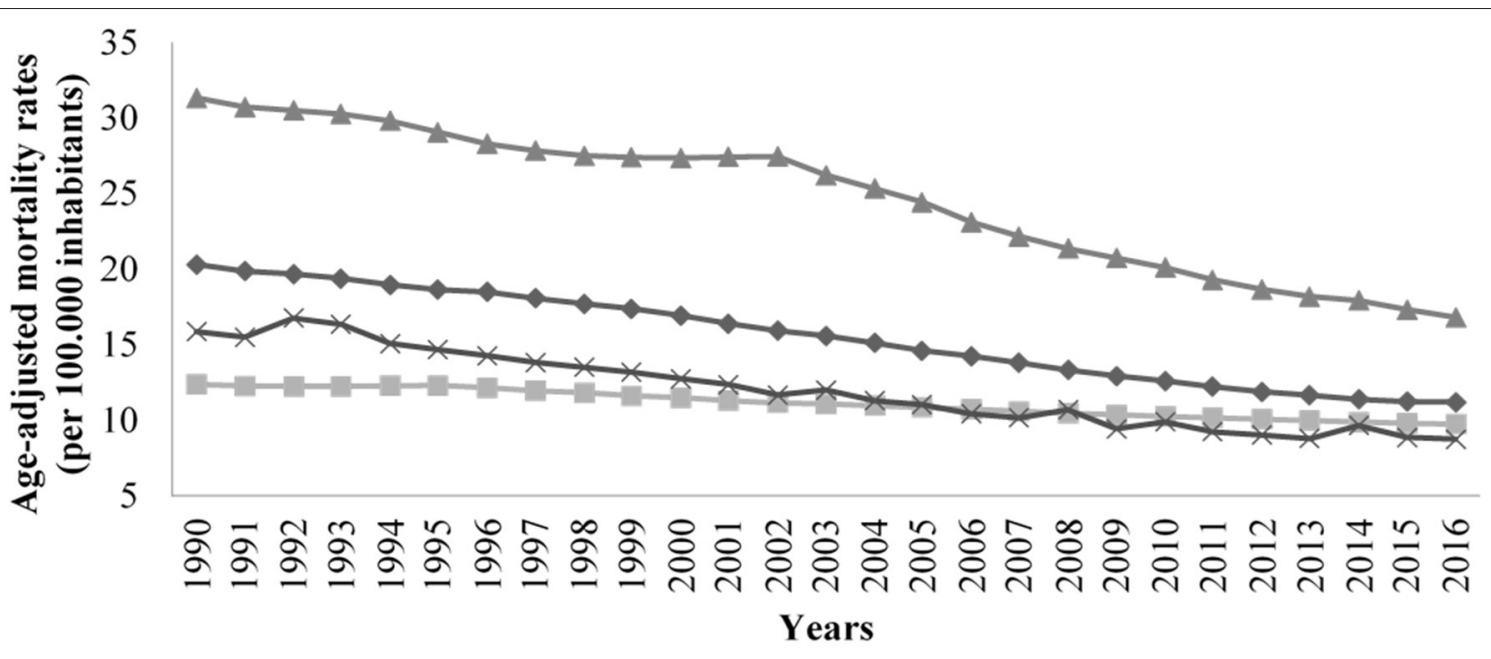

$\multimap$ Brazil $\longrightarrow$ Low income $\longrightarrow$ Middle income $\longleftarrow$ High income

FIGURE 1 | Trends of age adjusted mortality rates related to stomach cancer (per 100,000 inhabitants) in Brazil and low, middle, high income countries, 1990 to 2016.

TABLE 2 | Estimates of temporal trend of specific mortality rates for stomach cancer according to cut-off points obtained through the joinpoint. 1990-2016.

\begin{tabular}{lcccc}
\hline & Period & AAPC $(95 \% \mathbf{C l})$ & APC $(95 \% \mathbf{C l})$ & $p$-value \\
\hline Brazil & $1990-2003$ & $-2.3(-2.4 ;-2.2)$ & $-1.8(-1.9 ;-1.7)$ & $<0.001$ \\
Low income & $2003-2016$ & & $-2.8(-3.0 ;-2.7)$ & $<0.001$ \\
& $1990-2004$ & $-1.4(-1.5 ;-1.3)$ & $-1.8(-1.8 ;-1.7)$ & $<0.001$ \\
& $2004-2013$ & & $-1.2(-1.3 ;-1.0)$ & $<0.001$ \\
& $2013-2016$ & & $-0.4(-1.1 ;-0.4)^{\mathrm{a}}$ & 0.3 \\
Middle income & $1990-1997$ & $-2.1(-2.1 ;-2.0)$ & $-1.8(-2.0 ;-1.7)$ & $<0.001$ \\
& $1997-2004$ & & $-0.9(-1.1 ;-0.8)$ & $<0.001$ \\
& $2004-2007$ & & $-5.4(-6.3 ;-4.6)$ & $<0.001$ \\
& $2007-2010$ & & $-1.8(-2.7 ;-1.0)$ & $<0.001$ \\
& $2010-2013$ & & $-3.3(-4.2 ;-2.5)$ & $<0.001$ \\
& $2013-2016$ & & $-0.7(-1.2 ;-0.3)$ & $<0.001$ \\
High income & $1990-1995$ & $-2.7(-2.8 ;-2.6)$ & $-2.6(-3.0 ;-2.2)$ & $<0.001$ \\
& $1995-2006$ & & $-3.0(-3.1 ;-2.9)$ & $<0.001$ \\
& $2006-2016$ & & $-2.5(-2.6 ;-2.4)$ & $<0.001$ \\
\hline
\end{tabular}

Cl, confidence interval; APC, Annual Percent Change; AAPC, Average Annual Percent Change. ${ }^{a}$ The APC is not statistically significant $(p>0.05)$.

statuses studied (low, middle, and high income) and in Brazil, which showed a similar trend to that observed in middleincome countries.

The decrease in mortality in all socioeconomic statuses studied can be explained by the improvement in the population living conditions. Even in poorer countries, there has been improvement in social and economic aspects in recent decades (21).

Despite the improvements, epidemiological studies have found relationships between low socioeconomic status in childhood and the development of stomach cancer in adult life. One of the possibilities would be an early infection by $H$. pylori bacteria $(22,23)$. In view of this, it is to be understood that changes in mortality rates in low- and middleincome countries still tend to bear the consequences of this socioeconomic condition over a given time, even if they have already been overcome.

Over time, Brazil presented similar variations to all highincome countries, and in some periods of the series studied, variations were found in both low-income and middle- and high-income countries.

However, the mortality rates presented in Brazil are similar to the rates of middle-income countries and higher than those of some high-income countries $(5,24)$. This is because despite the high incidence in countries such as Japan, China, and South Korea, the diagnosis of stomach cancer occurs early, which reduces mortality (25).

On the other hand, some factors may explain the higher mortality in Brazil. Cancers of infectious origin, such as the stomach, are common in Latin countries due to economic development, and the Brazilian health system has no guidelines for screening. One of the main aspects that is directly involved with cases of stomach cancer deaths in Brazil is the inequality related to economic, geographic, and socio-cultural issues $(5,26,27)$.

Despite the drop in stomach cancer mortality in Brazil, the cases are still high and projections show an increase in the less developed regions of the country $(4,5)$. This fact underscores the importance of studies that take into account the geographical distribution, especially in countries such as Brazil, characterized by large socioeconomic discrepancies between regions.

It is important to emphasize that the territorial extension of Brazil also has an impact on the difficulty of professional qualification, access to health services and treatment funds, 
important factors for early detection, clinical management, and patient survival $(26,28)$.

Another important issue to consider in the current scenario of stomach cancer in the country and that is directly related to territorial extension was the lack of standardization in the diagnosis, staging, and treatment in the study period (26), key factors in achieving good treatment results (29). Only in $2018 \mathrm{did}$ Brazil approve diagnostic and therapeutic guidelines for stomach adenocarcinoma, which is the most common type of gastric cancer, accounting for about $90 \%$ of diagnosed cases (30).

Brazil presents a process of demographic and epidemiological transition that occurs differently depending on its Federative Units due to its socioeconomic disparities (31).

The North and Northeast regions present characteristics of low and middle income countries, such as high mortality rates due to infectious diseases (32), worse sanitation conditions (33) and a larger proportion of population residing in rural areas (34).

In contrast, the Midwest, South, and Southeast regions have characteristics of high income countries, such as the increase of chronic diseases such as obesity (35), the increase in life expectancy and, therefore, a more aged population (36).

This scenario shows that Brazil encompasses several factors that may influence the burden of stomach cancer. It is important to identify what local socioeconomic characteristics are related to the disease, which is a crucial starting point for the change of scenery in the country.

The limitations of this study are related to the use of secondary data, in which the researcher does not have control of data quality. However, despite being a constraint, we believe that because it is a database produced by important institutions and the database is used in scientific articles published in high impact journals, the findings support the reliability and validity of this data.

\section{REFERENCES}

1. Kamangar F, Dores GM, Anderson WF. Patterns of cancer incidence, mortality, and prevalence across five continents: defining priorities to reduce cancer disparities in different geographic regions of the world. J Clin Oncol. (2006) 24:2137-50. doi: 10.1200/JCO.2005.05.2308

2. Fielding JW, Ellis DJ, Jones BG, Paterson J, Powell DJ, Waterhouse JA, et al. Natural history of " early" gastric cancer: results of a 10-year regional survey. Br Med J. (1980) 281:965-67. doi: 10.1136/bmj.281.6246.965

3. Ang TL, Fock KM. Clinical epidemiology of gastric cancer. Singapore Med J. (2014) 55:621. doi: 10.11622/smedj.2014174

4. Chatenoud L, Bertuccio P, Bosetti C, Levi F, Curado MP, Malvezzi M, et al. Trends in cancer mortality in Brazil, 1980-2004. Europ J Cancer Prevent. (2010) 19:79-86. doi: 10.1097/CEJ.0b013e32833233be

5. de Souza Giusti ACB, de Oliveira Salvador PTC, Dos Santos J, Meira KC, Camacho AR, Guimarães RM, et al. Trends and predictions for gastric cancer mortality in Brazil. World J Gastroenterol. (2016) 22:6527. doi: 10.3748/wjg.v22.i28.6527

6. Koifman S, Koifman RJ. Stomach cancer incidence in Brazil: an ecologic study with selected risk factors. Cad de saude Publica. (1997) 13:S8592. doi: 10.1590/S0102-311X1997000500009

7. Muñoz N. Aspects of gastric cancer epidemiology with special reference to Latin America and Brazil. Cad de saude Publica. (1997) 13:S109. doi: 10.1590/S0102-311X1997000500013

\section{CONCLUSION}

Over time, Brazil shows a constant decline, with periods of variation similar to the behavior observed in both high and low income countries. Additionally, the findings of this study point to the need to understand the behavior of stomach cancer mortality in the regions and federal states of Brazil, since they present different socioeconomic characteristics.

\section{DATA AVAILABILITY STATEMENT}

Publicly available datasets were analyzed in this study. This data can be found at: http://ghdx.healthdata.org/gbd-results-tool.

\section{AUTHOR CONTRIBUTIONS}

SF conceived the study, analyzed the data, constructed the results from the data, and wrote the manuscript. WM analyzed the data, constructed the results from the data, and wrote the manuscript. KT collected the data and constructed the results from the data. FF conceived the study, analyzed the data, and reviewed results. FA conceived the study and reviewed results. All authors read and approved the final manuscript.

\section{FUNDING}

This work was supported by National Council for Scientific and Technological Development (CNPq)-FA was CNPq research productivity scholarship (Process Number 307183/2018-1).

\section{ACKNOWLEDGMENTS}

Federal University of South and Southeast Pará (UNIFESSPA)for the institutional support to SF.

8. dos Santos Figueiredo FW, Adami F. Income inequality and mortality owing to breast cancer: evidence from Brazil. Clin Breast Cancer. (2018) 18:e6518. doi: 10.1016/j.clbc.2017.11.005

9. Atun R, De Andrade LOM, Almeida G, Cotlear D, Dmytraczenko T, Frenz $\mathrm{P}$, et al. Health-system reform and universal health coverage in Latin America. Lancet. (2015) 385:1230-47. doi: 10.1016/S0140-6736(14)61 646-9

10. Marmot M. Brazil: rapid progress and the challenge of inequality. Int J Equity Health. (2016) 15:1-2. doi: 10.1186/s12939-016-0465-y

11. Silva ICMD, Restrepo-Mendez MC, Costa JC, Ewerling F, Hellwig F, Ferreira L, et al. Measurement of social inequalities in health: concepts and methodological approaches in the Brazilian context. Epidemiol Serv Saúde. (2018) 27:e000100017. doi: 10.5123/S1679-49742018000100017

12. Santos AMAD, Jacinto PDA, Tejada CAO. Causalidade entre renda e saúde: uma análise através da abordagem de dados em painel com os estados do Brasil. Estudos Econ. (2012) 42:229-61. doi: 10.1590/S0101-41612012000200001

13. Beghin N. Notes on inequality and poverty in Brazil: current situation and challenges. In: Green D, editor. From Poverty to Power: How Active Citizens and Effective States Can Change the World. Oxford: Oxfam International (2008). p. 1-6.

14. Silva SAD. Regional inequalities in Brazil: divergent readings on their origin and public policy design. EchoGéo. (2017) 41:315-40. doi: 10.4000/echogeo.15060 
15. Bucciferro JR, de Souza PHF. The evolution of regional income inequality in Brazil, 1872-2015. In: Deng K, editor. Time and Space. Cham: Palgrave Macmillan (2020). p. 131-56. doi: 10.1007/978-3-030-47553-6_6

16. dos Santos Figueiredo FW, do Carmo Almeida TC, Cardial DT, da Silva Maciel É, Fonseca FLA, Adami F. The role of health policy in the burden of breast cancer in Brazil. BMC Women's Health. (2017) 17:121. doi: 10.1186/s12905-017-0477-9

17. Institute for Health Metrics and Evaluation (IHME). A Protocol for the Global Burden of Diseases, Injuries, and Risk Factors Study (GBD). Seattle, WA: IHME, University of Washington (2020).

18. Global Burden of Disease Collaborative Network. Global Burden of Disease Study 2015 (GBD 2015) Socio-Demographic Index (SDI) 1980-2015. Seattle, WA: Institute for Health Metrics and Evaluation (IHME) (2016).

19. Joinpoint Regression Program, Version 4.8.0.1. Statistical Methodology and Applications Branch, Surveillance Research Program. Bethesda, MD: National Cancer Institute (2020).

20. Kim HJ, Fay MP, Feuer EJ, Midthune DN. Permutation tests for joinpoint regression with applications to cancer rates. Statist Med. (2000) 19:33551. doi: 10.1002/(sici)1097-0258(20000215)19:3<335::aid-sim336>3.0.co;2-z

21. Sinding SW. Population, poverty and economic development. Philo Trans R Soc B Biol Sci. (2009) 364:3023-30. doi: 10.1098/rstb.2009 .0145

22. Zali H, Rezaei-Tavirani M, Azodi M. Gastric cancer: prevention, risk factors and treatment. Gastroenterol Hepatol Bed Bench. (2011) 4:175-85. doi: $10.22037 /$ ghfbb.v4i4.193

23. Mihmanli M, Ilhan E, Idiz UO, Alemdar A, Demir U. Recent developments and innovations in gastric cancer. World J Gastroenterol. (2016) 22:4307. doi: 10.3748/wjg.v22.i17.4307

24. Sierra MS, Cueva P, Bravo LE, Forman D. Stomach cancer burden in Central and South America. Cancer Epidemiol. (2016) 44:S62-73. doi: 10.1016/j.canep.2016.03.008

25. Carcas LP. Gastric cancer review. J Carcinog. (2014) 13:14. doi: 10.4103/1477-3163.146506

26. Zilberstein B, Malheiros C, Lourenço LG, Kassab P, Jacob CE, Weston $\mathrm{AC}$, et al. Consenso brasileiro sobre câncer gástrico: diretrizes para o câncer gástrico no Brasil. ABCD. Arq Bras Cir Dig. (2013) 26:26. doi: 10.1590/S0102-67202013000100002

27. De Martel C, Ferlay J, Franceschi S, Vignat J, Bray F, Forman $\mathrm{D}$, et al. Global burden of cancers attributable to infections in 2008: a review and synthetic analysis. Lancet Oncol. (2012) 13:607-15. doi: 10.1016/S1470-2045(12)70137-7
28. Nagini S. Carcinoma of the stomach: a review of epidemiology, pathogenesis, molecular genetics and chemoprevention. World J Gastrointestinal Oncol. (2012) 4:156. doi: 10.4251/wjgo.v4.i7.156

29. Muraro CLPM. Câncer gástrico precoce: contribuição ao diagnóstico e resultado do tratamento cirúrgico. Rev Col Bras Cir. (2003) 30:3528. doi: 10.1590/S0100-69912003000500005

30. Brasil. Diretrizes Diagnósticas e Terapôuticas do Adenocarcinoma de Estômago. Brasília: Ministério da Saúde (2018).

31. Marinho F, de Azeredo Passos VM, Malta DC, França EB, Abreu DM, Araújo VE, et al. Burden of disease in Brazil, 1990-2016: a systematic subnational analysis for the Global Burden of Disease Study 2016. Lancet. (2018) 392:76075. doi: 10.1016/S0140-6736(18)31221-2

32. Kerr-Pontes LR, Barreto ML, Evangelista CM, Rodrigues LC, Heukelbach J, Feldmeier H. Socioeconomic, environmental, and behavioural risk factors for leprosy in North-east Brazil: results of a case-control study. Int J Epidemiol. (2006) 35:994-1000. doi: 10.1093/ije/dyl072

33. Mantovani SA, Delfino BM, Martins AC, Oliart-Guzmán H, Pereira TM, Branco FL, et al. Socioeconomic inequities and hepatitis A virus infection in Western Brazilian Amazonian children: spatial distribution and associated factors. BMC Infect Dis. (2015) 15:428. doi: 10.1186/s12879-0151164-9

34. Maia AG, Buainain AM. O novo mapa da população rural brasileira. Confins (2015) 25:1-17. doi: 10.4000/confins. 10548

35. Santos LMP, De Oliveira IV, Peters LR, Conde WL. Trends in morbid obesity and in bariatric surgeries covered by the Brazilian public health system. Obes Surg. (2010) 20:943-8. doi: 10.1007/s11695-008-9570-3

36. Paes NA. Elderly mortality in Brazil: trends, differentials, causes and links with socioeconomic indicators. In: 24th IUSSP General Population Conference. Salvador, BA (2001).

Conflict of Interest: The authors declare that the research was conducted in the absence of any commercial or financial relationships that could be construed as a potential conflict of interest.

Copyright (c) 2021 Farias, Maia Neto, Tomaz, Figueiredo and Adami. This is an open-access article distributed under the terms of the Creative Commons Attribution License (CC BY). The use, distribution or reproduction in other forums is permitted, provided the original author(s) and the copyright owner(s) are credited and that the original publication in this journal is cited, in accordance with accepted academic practice. No use, distribution or reproduction is permitted which does not comply with these terms. 